\title{
Correlation between the distance of maxillary central incisors and incisive papilla in different arch form
}

\author{
Nur Atteyya Natasha Mohd Zali *, Rasmi Rikmasari*, Hasna Dziab* \\ *Department of Prosthodontics Faculty Of Dentistry Universitas Padjadjaran, Indonesia
}

\begin{abstract}
In edentulous treatment, relocation of anterior teeth in the preexisting natural position is the utmost importance. It is necessary to refer to the significant anatomical landmarks, one of them is incisive papilla. To make it more efficient both functionally and biologically, the teeth were arranged in particular geometric manner known as a dental arch. The author has chosen to conducted the research among the Malay race represented by the Malay undergraduate students. The purpose of this study was to evaluate the correlation between the distance of maxillary central incisors and incisive papilla (CI-IP) in different arch form and gender. Maxillary impressions of 34 dentate individuals were taken, and the measurements were performed using a digital caliper. The results showed the $\mathrm{Cl}$-IP distance was ranging between 7.65 to $9.90 \mathrm{~mm}$, with the average of $8.77 \mathrm{~mm}$. There was no significant difference of the $\mathrm{Cl}-\mathrm{IP}$ distance between male and female regardless of their arch forms $(p>0.05)$. Individuals with ovoid and tapered arch form, however, showed a significant difference of the CI-IP distance between male and female $(p<0.05)$. Meanwhile, Individuals with square arch form showed no significant difference of the $\mathrm{Cl}$-IP distance between male and female ( $p>0.05)$. It can be concluded that gender factor was irrelevant towards the $\mathrm{Cl}-\mathrm{IP}$ distance regardless of the individual arch form. However, there was a correlation between the CI-IP distance in different arch forms in both male and female sample.
\end{abstract}

Keywords: Incisive papilla, arch form, maxillary central incisors

\section{INTRODUCTION}

The increasing level of dental awareness in the community has decreased the total edentulism case due to increasing number of edentulous patients seeking treatment. The reasons for having treatment may vary, but the predominant reason was appearance improvement. ${ }^{1}$ Also, it is clear that the increasing demand for edentulous treatment also escalated the patient's expectations, therefore, required a high-qualified skill of the dentists. ${ }^{2}$

Prosthodontists who treat a large number of edentulous patients realize that some patients cannot be satisfied aesthetically, functionally or both. For these patients, even a more objective selection criteria will be unsuccessful. However, for the majority of edentulous patients, a simple objective technique involving anatomical measurements would provide at least a starting point for tooth selection. ${ }^{3}$

Once the maxillary anterior teeth were chosen, the rest of the teeth can be selected, and the denture can be placed on their bases. The selection of anterior teeth formed the basis for selecting tooth position will, therefore, affect the entire. ${ }^{4}$ In spite of various methods, determination of correct selection and arrangement of maxillary 
anterior teeth has not defined yet. Although more advances in techniques and materials were made in prosthodontics, there is still no accurate method for selection and arrangement of the maxillary anterior teeth available for dentists. ${ }^{5}$ The key is the placement of the maxillary central incisors. The correct position of these teeth will directly influence the position of every denture.

Confirmation of anterior tooth position will be accomplished by referring to the anatomical landmarks such as the incisive papilla, preextraction records such as radiographic image, speech sounds, and patient's feedback. Without patient's dental record before the extraction performed, the selection of maxillary anterior teeth for the edentulous patient would be mostly subjective. To keep the premium aesthetical part, dentists should follow anatomic landmarks on assisting the relocation the original tooth position. ${ }^{4}$

The incisive papilla is a stable landmark that remains unchanged following the extraction of the maxillary anterior teeth. This landmark is used for assessing the position of maxillary incisors of the patient's denture, and as a biometric guideline in the placement of removable central incisors and maxillary dentures in a comprehensive denture therapy. The use of this biometric guideline is based on the need for the artificial anterior teeth settlement as close as possible to positions the edentulism and aligning the tooth arrangement in edentulism therapy thus improving the aesthetical aspect for the patient. ${ }^{6}$

Many factors such as hereditary factor, the bone growth, tooth eruption and inclination, external influences, function, and ethnic background could affect the size and shape of the dental arches. ${ }^{7}$ The differences in arch shape and dimension are able to affect the clinical treatment. Also, people from different ethnic groups will also have different morphological conditions, and clinicians should anticipate these differences rather than generalizing all cases to a single treatment. ${ }^{8}$

A parallel research has performed recently to determine the distance between maxillary central incisors with incisive papilla based on race and gender involving the students of Faculty of Dentistry Universitas Sumatera Utara, ${ }^{9}$ between Caucasians and Mongoloids male and female students, however, the researcher did not mention about the incisive papilla and maxillary central incisors correlation with different arch forms based on ethnicity. In the present as well as previous literature, the arch forms assessment was performed by their geometrical description.

Therefore, through this research, we intended to prove whether measurements of the incisive papilla and maxillary central incisors distance in dentate individuals would be able to provide meaningful guidelines for the maxillary anterior teeth arrangement in prosthodontics procedures for edentulous patients with similar dental arches. The research was conducted towards Malaysian Malay undergraduate students of Universitas Padjadjaran batch 2007 and 2008.

\section{METHODS}

This research was descriptive with analytical survey methods amongst the Malaysian Malay undergraduate students of Universitas Padjadjaran batch 2007 and 2008. The sample was taken with the random sampling method. The total number of the population was 255 , with 77 male and 178 female. The tools and materials used in this research were as follows: Rinsing cup; Mixing spatula; Rubber bowl; Alginate powder; Dental plaster; Various sizes of dental impression tray; Mouth mirror; Dental explorer; Tweezers; Le crown dental; Wax knife; and Digital caliper with $0.05 \mathrm{~mm}$ scale. First of all, the average distance from the centre of incisive papilla to the labial incisal of the one-third of central incisors in both male and female subjects was obtained using the mean and standard deviation formula. Then the average distance from the centre of incisive papilla to the labial incisal of the one-third of central incisors according to the arch form (square, ovoid, and tapered) was obtained. The value taken was analysed using a Student's t-distribution.

\section{RESULTS}

The study was conducted towards the total of 34 subjects selected using the random sampling method. The results obtained throughout this study were presented in Table 1 to Table 4. Table 1 showed that the ovoid arch form was the most common type of arch found in male and female subjects, with the value of $41.67 \%$ and $54.55 \%$, 
Table 1. Frequency distribution of different arch forms

\begin{tabular}{ccccc}
\hline \multirow{2}{*}{ Arch Form } & \multicolumn{2}{c}{ Male } & \multicolumn{2}{c}{ Female } \\
\cline { 2 - 5 } & $\mathrm{n}$ & $\%$ & $\mathrm{n}$ & $\%$ \\
\hline Ovoid & 5 & 41.67 & 12 & 54.55 \\
Square & 4 & 33.33 & 7 & 31.82 \\
Tapered & 3 & 25.00 & 3 & 13.64 \\
\hline Total & 12 & 100 & 22 & 100 \\
\hline
\end{tabular}

Table 2. CI-IP distance based on gender

\begin{tabular}{cccccc}
\hline \multicolumn{5}{c}{ Male } & \multicolumn{2}{c}{ Female } \\
\hline Range & Mean \pm SD & Range & Mean \pm SD & t-value & p-value \\
\hline $7.62-9.90$ & $9.02 \pm 0.64$ & $7.65-9.30$ & $8.68 \pm 0.36$ & 1.74 & $>0.05$ \\
\hline Reference & CI-IP $=$ Maxillary & \multicolumn{2}{c}{ central incisors-incisive } & papilla; SD & Standard deviation \\
\hline
\end{tabular}

Table 3. $\mathrm{Cl}-\mathrm{IP}$ distance based on gender and arch form

\begin{tabular}{ccccc}
\hline & \multicolumn{2}{c}{ Male } & \multicolumn{2}{c}{ Female } \\
\hline Arch form & Range $(\mathrm{mm})$ & Mean \pm SD $(\mathrm{mm})$ & Range $(\mathrm{mm})$ & Mean \pm SD $(\mathrm{mm})$ \\
\hline Ovoid & $8.85-9.22$ & $8.97 \pm 0.16$ & $8.25-9.16$ & $8.73 \pm 0.24$ \\
Square & $7.62-8.89$ & $8.49 \pm 0.60$ & $7.65-8.88$ & $8.42 \pm 0.44$ \\
Tapered & $9.80-9.90$ & $9.86 \pm 0.05$ & $8.88-9.30$ & $9.06 \pm 0.22$ \\
\hline
\end{tabular}

Table 4. CI-IP distance based on arch of both gender and arch form

\begin{tabular}{cccc}
\hline Male & Female & t-value & p-value \\
\cline { 1 - 2 } Mean \pm SD $(\mathrm{mm})$ & Mean \pm SD $(\mathrm{mm})$ & & \\
\hline $8.97 \pm 0.16$ & $8.73 \pm 0.24$ & 2.25 & $<0.05$ \\
$8.49 \pm 0.60$ & $8.42 \pm 0.44$ & 0.19 & $>0.05$ \\
$9.86 \pm 0.05$ & $9.06 \pm 0.22$ & 0.10 & $<0.05$ \\
\hline
\end{tabular}

respectively. The tapered arch form was the least common type of arch found in both genders, with the value of $25.00 \%$ in male and $13.64 \%$ in female, while the square arch form was found as much as $33.33 \%$ in male and $31.82 \%$ in female.

The mean and SD (standard deviation), of unpaired (independent) sample differences, and also the t-value and $\mathrm{p}$-value of the maxillary central incisors to incisive papilla (CI-IP) distance were described in Table 2 to Table 4. Table 2 showed the statistical analysis of data taken from male and female subjects. The $\mathrm{CI}$-IP distance of male sample was ranged from $7.62-9.90 \mathrm{~mm}$ with the average of $9.02 \mathrm{~mm}$ and standard deviation of \pm 0.64 . The $\mathrm{Cl}-\mathrm{IP}$ distance of female sample was ranged from $7.65-9.30 \mathrm{~mm}$ with the average of $8.68 \mathrm{~mm}$ and standard deviation of \pm 0.36 . The average value of male samples was higher than the average value of female samples. A low standard deviation indicated that the data points tend to be very close to the average value.

Table 3 and Table 4 showed the measurement of central incisor to incisive papilla (CI-IP) distance based on gender and arch form. The square arch form had the minimum $\mathrm{Cl}$-IP distance (ranged from $7.62-8.89 \mathrm{~mm}$ with the average of 8.49 in male, and ranged from $7.65-8.88 \mathrm{~mm}$ with the average of $8.42 \mathrm{~mm}$ in female). The tapered arch form had the maximum $\mathrm{Cl}-\mathrm{IP}$ distance (ranged from 9.80$9.90 \mathrm{~mm}$ with the average of 9.86 in male, and ranged from $8.88-9.30 \mathrm{~mm}$ with the average from $9.06 \mathrm{~mm}$ in female). The ovoid arch form had the $\mathrm{Cl}-\mathrm{IP}$ distance in the range of 8.85-9.22 $\mathrm{mm}$ with the average of $8.97 \mathrm{~mm}$ in male, and in the range of $8.25-9.16 \mathrm{~mm}$ with the average of 8.73 in female. 


\section{DISCUSSION}

The objective of this research was to evaluate any differences in the measurement of the $\mathrm{Cl}$-IP distance among the Malaysian Malay students based on gender and arch forms, also to determined whether the measurement of the $\mathrm{Cl}$-IP distance in dentate individuals were able to provide meaningful guidelines for maxillary anterior teeth arrangement while in prosthodontic procedures for patients with similar arch forms. The upper jaw impressions of as much as 34 dentate individuals with different arch form were taken. The measurements were performed using a digital caliper, and all the data has been interpreted.

The result of this study showed that the ovoid arch form was the most common type of arch form found in both male and female $(41.67 \%$ and $45.55 \%$ ). The square arch forms were the second type found after the ovoid forms in both genders $(33.33 \%$ in male and $31.82 \%$ in female). The tapered arch forms were found as much as $25.00 \%$ in male and $13.64 \%$ in female. Zia et al. ${ }^{3}$ conducted a study on 150 samples and also found that ovoid arch form was the most common type of arch form among Pakistani population $57.30 \%$ in male and $68.00 \%$ in female). However, Nakatsuka ${ }^{10}$ found that the most frequent arch form among Japanese was the round square. Kook ${ }^{11}$ had studied the difference between Korean (Mongoloid race) and North American (Caucasian race) populations and found that in the Caucasian population, the tapered arch form was predominated and the square arch form was predominated in the Korean population, and the Korean arches tended to be larger and deeper than Caucasian. Gafni et al. ${ }^{12}$ stated that the most frequent arch form of the Israeli group was found to be the ovoid form, as opposed to the North American group with the tapered form as the predominant form. The reason for these results was because the North American population had statistically significant lower arch widths and higher arch depths compared to the Israeli population.

The average $\mathrm{Cl}-\mathrm{IP}$ distance in both male and female subjects regardless of their arch forms were $9.02 \mathrm{~mm}$ and $8.68 \mathrm{~mm}$ respectively. The statistical analysis (unpaired sample t-test) result revealed that there was no significant difference $(p>0.05)$ in $\mathrm{Cl}-\mathrm{IP}$ distance in male and female subjects with ovoid, square and tapered arch forms $(p>0.05)$. This result meant that gender factor was an irrelevant factor of the $\mathrm{Cl}$ IP distance. This study was consistent with the findings of an earlier study stated that there was no significant difference between the $\mathrm{Cl}$-IP distance of both male and female regardless of their arch form. ${ }^{5,3,13,14}$ However, a study conducted by Seok ${ }^{15}$ and more recent study by Simanungkalit ${ }^{9}$ were contradicted with this study, which found that there was a significant difference between the $\mathrm{CI}$-IP distance of male and female subjects. In the research conducted by Simanungkalit discovered that in Mongoloid race, there was a significant difference of $\mathrm{Cl}$-IP distance between male and female $(p=0.036)$. However, in Caucasia race, there was no significant difference between male and female $(\mathrm{p}=0.0226)$.

In the ovoid arch form subjects, the average $\mathrm{Cl}$-IP distance in male was different from female, which was $8.97 \mathrm{~mm}$ and $8.73 \mathrm{~mm}$ respectively. The statistical analysis (unpaired sample t-test) result revealed that there was a significant difference $(\mathrm{p}<0.05)$ in the $\mathrm{Cl}-\mathrm{IP}$ distance between male and female subjects with ovoid arch form. In subjects with square arch form, a slight difference in the average value was observed $(8.49 \mathrm{~mm}$ in male and 8.42 in female). The statistical analysis result of the $p$-value resulted in $p>0.05$, meant that there was no significant difference in the $\mathrm{Cl}$-IP distance between male and female subjects with square arch form. In the tapered arch form subjects, the statistical analysis result revealed that there was a significant difference between male and female $(p<0.05)$ with the average value of 9.86 $\mathrm{mm}$ and $9.06 \mathrm{~mm}$ respectively. These results were consistent with the research conducted by Zia et al. ${ }^{3}$ In their research, they measured the distance between the mesial edges of the maxillary central incisors to the posterior border of the incisive papilla in dentate individuals with different arch forms. They discovered that individuals with ovoid and tapered arch forms showed a significant difference in the CI-IP distance between males and females $(p<0.05)$. In subjects with square forms, however, a slight difference in was found (no significant difference).

The distance from the center of the incisive papilla to the labio-incisal of the one-third of 
central incisor was ranged between 7.18-11.51 $\mathrm{mm}$, with the average of $9.21 \mathrm{~mm}^{16} \mathrm{In}$ the research conducted by Fu et al. in 2007 amongst young adults in Taiwan discovered that the mesiolabial incisal edge of the upper central incisor was $7.30 \pm 0.64 \mathrm{~mm}$ anterior to the center of the incisive papilla. ${ }^{17}$ Elfadil's study in 2008 measured the distances from the labial surface of the central incisor to the center and posterior point of the incisive papilla. ${ }^{14}$ The data obtained suggested that the average distance of $12.4 \mathrm{~mm}$ when the posterior point of the incisive papilla was used as the reference point and $8.93 \mathrm{~mm}$ when the center of the papilla was used as the reference point.

Ortman and Tsao stated that the distance of the anterior part of the maxillary central incisors and the posterior of the incisive papilla was 12.45 mm. ${ }^{18}$ Also, Grave and Becker in 1987 have proved this similar measurement, which was as much as $12-13 \mathrm{~mm} .{ }^{19}$ Lassila et al. discovered that the measurement of the anterior part of the maxillary central incisors and the posterior of the incisive papilla was $12 \mathrm{~mm}$. The measurement methods of all these studies were a two-dimensional method. ${ }^{20}$ However, Park et al. in 2007 suggested similar results $(11.96 \pm 1.37) \mathrm{mm}$ with the threedimensional measurement method, with a virtual model of the maxillary anterior teeth and incisive papilla. The results of these studies using both two and three-dimensional measuring methods showed that both methods were reliable. ${ }^{21}$

Chalsuthipan and Boonsiri investigated the relationship between the incisive papilla, maxillary central incisors, and canines in the Thai population. As much as 360 selected maxillary models were analyzed in their study. ${ }^{22}$ In this study, we found that the vertical distance from the most distal point of the incisive papilla to the incisal edge of the central incisors was ranged from $6.94-7.23 \mathrm{~mm}$ with the average of $7.08 \mathrm{~mm}$. Guldag et al. in 2008 discovered that the average vertical distance between the maxillary central incisors and the midpoint of the incisive papilla on the stone casts was $6.70 \pm 0.81 \mathrm{~mm}$. The vertical distance was ranged from $5.51-8.89 \mathrm{~mm} .^{23}$

The average value variation may caused by the reference point differences on the incisive papilla because some researchers used the most posterior border of the incisive papilla. The most posterior part of incisive papilla was the farthest from the occlusal plane and the maxillary central incisors. ${ }^{23}$

In 1993, Lau and Clark studied the relationship of the incisive papilla to the maxillary central incisors and the canine in the Southern Chinese population. ${ }^{24}$ The results showed that there was a slight difference between the Southern Chinese population and other most ethnic groups. The guidelines used was the incisive papilla as a reference for the setting of denture construction recommended for Caucasians, and was able to applied to the Southern Chinese patients. Elfadil in 2008 also mentioned that in his study amongst Sudanese population showed insignificant differences compared to other ethnic groups. ${ }^{14}$

Overall, the distance from the center of incisive papilla to the labio-incisal of the onethird of central incisors among the Malaysian Malay students was ranged between 7.65-9.90 $\mathrm{mm}$, with the average of $8.77 \mathrm{~mm}$. There was no significant difference in the $\mathrm{Cl}$-IP distance between male and female subjects regardless of their arch form. Individuals with ovoid and tapered arch forms showed a significant difference in the $\mathrm{Cl}$ IP distance between male and female $(p<0.05)$. Meanwhile, individuals with square arch forms showed no significant difference in the $\mathrm{Cl}-\mathrm{IP}$ distance between male and female ( $p>0.05)$.

The guidelines used was the incisive papilla as a reference for the setting of denture construction recommended for Caucasians that was able to applied for Mongoloid patients. ${ }^{24}$ However, the wax rims should be modified intraorally to incorporate individual characteristics, and the anterior teeth should be arranged on the modified wax rims. ${ }^{23}$ The bases carried the occlusion rims should be rigid and stable. The upper rim was modified to give the correct lip support. The incisive papilla provides a useful biometric guide to the prominence of the rim. Patients' wishes, or previous satisfactory dentures, may dictate otherwise.

\section{CONCLUSION}

Gender was an irrelevant factor of the $\mathrm{Cl}$ IP distance regardless of individual arch forms, but there was a correlation between the $\mathrm{Cl}$-IP distance with different arch forms in both male and female subjects. 


\section{REFERENCES}

1. Owen CP. Fundamentals of Removable Partial Dentures. $2^{\text {nd }}$ ed. Cape Town: Juta Academic; 2000. p. 1.

2. McCord JF, Grant AA, Youngson CC, Watson RM, Davis DM. Missing Teeth: A Guide to Treatment Options. London: Churchill Livingstone; 2003. p. 1.

3. Zia M, Azad AA, Ahmed S. Comparison of distance between maxillary central incisors and incisive papilla in dentate individuals with different arch forms. J Ayub Med Coll Abbottabad. 2009 Oct-Dec;21(4):125-8.

4. West Virgina University Libraries [homepage on internet]. Morgantown: Davis BA. 2005. Anatomical measurements of orthodontic and edentulous casts to determine the width of the maxillary anterior teeth. [cited 2011 Apr]; [about 1 screen]. Available from: http:// wvuscholar.wvu.edu:8881//exlibris/dtl/ d3_1/apache_media/L2V4bGlicmlz2R0b/

5. Rajiv Gandhi University of Health Sciences [homepage on internet]. Bangalore: Qazi SN. 2006. Nasal width, intercanine distance and incisive papilla as guides for selection and arrangement of maxillary anterior teeth. [cited 2011 Apr]; [about 2 screens]. Available from: http://shazana\%20nasal\%20 papilla\&ei=57oToaiHMS3ren2ljOCg\&usg=AF/ .

6. International \& American Dental Research [homepage on internet]. Alexandria, VA: Kathree A, Wilson VJ, Solomons CS. 2006. Biometric relationship between the incisive papilla and maxillary central incisors. [cited 2011 Jun]; [about 2 screens]. Available from: http: / / iadr.confex.com/iadr/safdiv03/ liminaryprogram/abstract65559.htm/.

7. Al-Khateeb SN, Abu Alhaija ES. Tooth size discrepancies and arch parameters among different malocclusions in a Jordanian sample. Angle Orthod. 2006 May;76(3):459-65.

8. Burris BG, Harris EF. Maxillary arch size and shape in American blacks and whites. Angle Orthod. 2000 Aug;70(4):297-302.

9. Simanungkalit P. Perbedaan jarak antara gigi insisivus sentralis rahang atas dengan papila insisivum berdasarkan ras dan jenis kelamin pada mahasiswa FKG USU Angkatan 2007 dan 2008 [minor thesis]. Medan: USU. 2010.
10. Nakatsuka M, Iwai Y, Jue SS, Oh SH, Guo L, Tominaga $Y$, et al. A morphological study on the classification of maxillary dental arches. Okajimas Folia Anat Jpn. 2004 May;81(1):5-13.

11. Kook YA, Nojima K, Moon HB, McLaughlin RP, Sinclair PM. Comparison of arch forms between Korean and North American white populations. Am J Orthod Dentofacial Orthop. 126:680-6.

12. Gafni Y, Tzur-Gadassi L, Nojima K, McLaughlin RP, Abed Y, Redlich M. Comparison of arch forms between Israeli and North American white populations. Am J Orthod Dentofacial Orthop. 2004 Dec;126(6):680-6.

13. Amin WM, Taha ST, Al-Tarawneh SK, Saleh MW, Ghzawi A. The relationships of the maxillary central incisors and canines to the incisive papilla in Jordanians. J Contemp Dent Pract. 2008 Jul 1;9(5):42-51.

14. Idris RAE. The incisive papilla as a guide for anterior teeth arrangement [thesis]. Khartoum: University of Khartoum. 2002.

15. Seok HY, Wan SS. A study on the positioning of the maxillary central incisor in Korean. J Korean Acad Prost. 1995;33:85-97.

16. Huang SJ, Chou TM, Lee HE, Wu YC, Yang YH, Ho $C D$, et al. Exploring the Distance between Upper Central Incisor Edge and Incisive Papilla in Taiwanese Population. Taiwan J Oral Med Health Sci. 2004;20:4-10.

17. Fu PS, Hung CC, Hong JM, Wang JC, Tsai CF, Wu YM. Three-dimensional relationship of the maxillary anterior teeth to the incisive papilla in young adults. Kaohsiung J Med Sci. 2007 Oct;23(10):519-25.

18. Ortman HR, Tsao DH. Relationship of the incisive papilla to the maxillary central incisors. J Prosthet Dent. 1979 Nov;42(5):4926.

19. Grave AM, Becker PJ. Evaluation of the incisive papilla as a guide to anterior tooth position. J Prosthet Dent. 1987 Jun;57(6):712-4.

20. Lassila LV, Klemetti E, Lassila VP. Position of teeth on the edentulous atrophic maxilla. J Oral Rehabil. 2001 Mar;28(3):267-72.

21. Park YS, Lee SP, Paik KS. The three-dimensional relationship on a virtual model between the maxillary anterior teeth and incisive papilla. J Prosthet Dent. 2007 Oct;98(4):312-8.

22. Chalsuthipan S, Boonsiri I. Relationship of 
central incisor and canine to incisive papilla. Chulalongkorn Univ Dent J. 1993;16:29-40.

23. Guldag MU, Sentut F, Buyukkaplan US. Investigation of vertical distance between incisive papilla and incisal edge of maxillary central incisors. Eur J Dent. 2008 Jul 2:161-6.

24. Lau GC, Clark RF. The relationship of the incisive papilla to the maxillary central incisors and canine teeth in southern Chinese. J Prosthet Dent. 1993 Jul;70(1):86-93. 